\title{
ФОРМЫ РЕОРГАНИЗАЦИИ В СИСТЕМЕ И СТРУКТУРЕ ФЕДЕРАЛЬНЫХ ОРГАНОВ ИСПОЛНИТЕЛЬНОЙ ВЛАСТИ
}

\begin{abstract}
Аннотация: В качестве предмета исследования выступают организационно-правовые основы реорганизации федеральных органов исполнительной власти. Автор исследует различные формы реорганизации органов исполнительной власти, в том числе образование, преобразование, присоединение, переименование, упразднение, а также соотносит их с формами реорганизации юридических лиц. Каждая форма реорганизации иллюстрируется актуальными примерами изменений, произошедших в недавнее время в системе государственного управления. Особую роль 8 исследовании занимает роль Президента Российской Федерации в определении правовых основ функционирования федеральных органов исполнительной власти. При проведении исследования использовались формально-юридический, структурно- функииональный, исторический илингвистическийметоды, которые позволили обеспечить комплексное изучение проблематики реорганизации в системе федеральных органов исполнительной власти. К основным выводам исследования можно отнести обоснованную необходимость принятия федерального закона «О федеральных органах исполнительной власти», сформулированные правовые и политические риски подзаконного регулирования системы и структуры федеральных органов исполнительной власти, систематизированные формы реорганизаџии федеральных органов исполнительной власти. Также необходимо отметить вывод о различии сущности в преобразовании юридических лии и федеральных органов исполнительной власти.
\end{abstract}

Ключевые слова: Органы исполнительной власти, министерства, службы, агентства, правительство, президент, трансформация, реорганизация, административная реформа, правовое регулирование.

Abstract: The subject of this research is the organizational and legal bases of reorganization of the federal branches of executive authority. The author examines various forms of reorganization of the executive branches of government, including foundation, transformation, merger, renaming, abolition, and compares them with the forms of reorganization of corporations. Each form of reorganization is illustrated by actual examples of the changes that have recently taken place within government administration. A special role in this research is played by the President of the Russian Federation in determination of the legal foundation of the functionality of the federal branches of executive authority. Among the main conclusions are the substantiated need to pass a federal law "On Federal Branches of Executive Authority"; formulated legal and political risks of the legal regulation of the systems and structure of the federal branches of executive authority; systematized forms of reorganization of federal branches of executive authority. Another noteworthy conclusion is on the difference between the nature of transformation within corporate structures, and the branches of executive authority.

Keywords: Reorganization, transformation, president, government, agencies, services, ministries, executive authorities, administrative reform, legal regulation.

B отечественной юридической науке достаточно хорошо изучены вопросы реорганизации юридических лиц, при этом проблематика реорганизации органов власти, в частности, органов исполнительной власти, в целом остаётся за рамками правовых исследований; в основном такие исследования сконцентрированы на исследовании особенностей наделения органов государственной власти статусом юридического лица [1]. В рамках данной статьи основной акцент делается на реорганизацию в трёхвидовой системе и структуре федеральных органов исполнительной власти, при этом не затрагивая изменения, происходящие с точки зрения организации работы Правительства Российской Федерации.
В соответствии со ст. 124 Гражданского кодекса к Российской Федерации применяются нормы гражданского законодательства о юридических лицах, если иное не предусмотрено законом или особенностями статуса данных субъектов, при этом на основании ст. 125 ГК органы государственной власти могут от имени Российской Федерации своими действиями приобретать и осуществлять имущественные и личные неимущественные права и обязанности, выступать в суде в рамках установленной компетенции. Правовой статус федеральных органов исполнительной власти, закрепляется в соответствующих положениях о них, утверждаемых в зависимости от подведомственности указами Президента Российской Федерации либо по- 
DOI: $10.7256 / 1811-9018.2015 .9 .15938$

При цитировании этой статьи сноска на доі обязательна

\section{Право и политика 9 (189) 2015}

становлениями Правительства Российской Федерации. Так, например, в соответствии с п. 13 Указа Президента Российской Федерации от 11 июля 2004 г. № 865 «Вопросы Министерства иностранных дел Российской Федерации» МИД России является юридическим лицом. И несмотря на то, что органы исполнительной власти в целом обладают статусом юридического лица, существуют значительные особенности их правового статуса и реорганизации [2].

Изучение правового статуса федерального органа исполнительной власти с точки зрения отнесения его к юридическому лицу в рамках данного исследования не случайно, поскольку Гражданский кодекс в ст. 57 закрепляет следующие формы реорганизации: слияние, присоединение, выделение, преобразование. Но при этом возникает обоснованный вопрос, насколько упомянутые формы, хотя бы терминологически, могут применяться к органам исполнительной власти как к юридическим лицам? Ответ на данный вопрос можно найти в тексте Указа Президента Российской Федерации от 9 марта 2004 г. № 314 «О системе и структуре федеральных органов исполнительной власти», в котором использованы иные формы реорганизации: образование, преобразование, переименование, упразднение. Указ Президента Российской Федерации от 4 марта 2011 г. № 270 содержит упоминание такое формы реорганизации, как присоединение [3]. Таким образом, в части реорганизации в отношении федеральных органов исполнительной власти используются в значительной степени иной понятийный аппарат.

Но принципиальное отличие в реорганизации юридических лиц от реорганизации органов исполнительной власти заключается в том, что в подавляющем большинстве случаев реорганизация юридического лица затрагивает непосредственно деятельность этого юридического лица, в то же самое время реорганизация органа исполнительной власти затрагивает весь механизм государственного управления, так как функции органа исполнительной власти являются объективно обусловленными и не могут «повисать в воздухе», оставаясь неохваченными деятельностью того или иного органа власти.

Вопреки устоявшейся практике, в Конституции Российской Федерации напрямую не закреплены полномочия Президента Российской Федерации по определению системы и структуры федеральных органов исполнительной власти. Пункт «Г» статьи 71 Конституции относит к вопросам ведения Российской Федерации установление федеральных органов исполнительной власти, порядок их организации и деятельности, а также формирование федеральных органов государственной власти. При этом ч. 1 ст. 76 Конституции предусматривает, что по предметам ведения Российской Федерации принимаются федеральные конституционные законы и федеральные законы. Также Конституция в ст. 112 предусматривает, что Председатель Правительства не позднее недельного срока после назначения представляет предложения Президенту Российской Федерации предложения о структуре федеральных органов исполнительной власти. Таким образом, Конституция не содержит положений, прямо устанавливающих то, что Президент Российской Федерации имеет право образовывать, преобразовывать или упразднять федеральные органы исполнительной власти.

Именно указанное выше обстоятельство послужило основанием для направления запроса Государственной Думы в Конституционный Суд Российской Федерации, который в своём постановлении от 27 января 1999 г. № 2-П «По делу о толковании статей 71 (пункт «Г»), 76 (часть 1) и 112 (часть 1) Конституции Российской Федерации» установил, что система федеральных органов исполнительной власти, в которую входят Правительство Российской Федерации, министерства и другие органы исполнительной власти, определяется на основании Конституции Российской Федерации, Федерального конституционного закона «О Правительстве Российской Федерации» и иных федеральных законов. Но в то же время по вопросам, касающимся системы федеральных органов исполнительной власти, не урегулированной законодателем, Президент Российской Федерации может издавать указы. Т.е. в данном случае ввиду отсутствия федерального законодательства, устанавливающего систему и структуру федеральных органов исполнительной власти, правовые основы их преобразований, Президент Российской Федерации своими указами устраняет «правовой вакуум». Таким образом, с правовой точки зрения абсолютно обоснованной представляется позиция о необходимости принятия федерального закона «О федеральных органах исполнительной власти Российской Федерации».

Очевидно, что несмотря на наличие всех правовых оснований для законодательного регулирования системы и структуры федеральных органов исполнительной власти, существуют политические предпосылки для отсутствия закона о федеральных органах исполнительной власти. Так подзаконное регулирование правового статуса федеральных органов исполнительной власти выводит их из-под прямого контроля и воздействия законодательной ветви власти, позволяет объективно 
быстрее производить изменения в системе и структуре федеральных органов исполнительной власти, перераспределять функции между федеральными органами исполнительной власти.

В силу сложившейся на данный момент практики, образование новых федеральных органов исполнительной власти осуществляется Президентом Российской Федерации в форме указа. Основной объём изменений в системе федеральных органов исполнительной происходит в момент начала очередного срока полномочий вновь избранного Президента, т.е. изменения системы и структуры федеральных органов исполнительной власти политически напрямую связаны с избирательным циклом в государстве. Таким образом, значительные изменения структуры происходили в 2000 [4], 2004 [5], 2008 [6], 2012 [7] годах; при этом в 2004 г. в контексте административной реформы было проведено кардинальное изменение системы: взамен многочисленных типов федеральных органов исполнительной власти (федеральных министерств, государственных комитетов, федеральных комиссий, федеральных служб, российских агентств, федеральных надзоров, главных управлений, государственных комиссий и др.) была создана трёхвидовая система, состоящая из федеральных министерств, агентств и служб. Но в то же время, начиная с 2004 года было принято более 30 (!) указов Президента Российской Федерации, так или иначе затрагивающих систему федеральных органов исполнительной власти.

После издания указа Президента об образовании нового федерального органа исполнительной власти, принимается положение об этом органе, которое утверждается либо указом Президента Российской Федерации (в случае, если создаваемый фоив входит в так называемый «административно-политический» блок и подчиняется Президенту), либо постановлением Правительства Российской Федерации (в случае, если создаваемый фоив входит в «социально-экономический» блок и руководство его деятельностью осуществляет Правительство). Причем между юридическим фактом принятия указа о создании федерального органа исполнительной власти и принятием положения о нем, в которым закрепляется правовой статус, может проходить весьма продолжительный промежуток времени. Так, например, Министерство по делам Крыма было образовано Указом Президента Российской Федерации от 31 марта 2014 г. № 190 [8], а соответствующее положение о Министерстве было утверждено только Постановлением Правительства Российской Федерации от 10 мая 2014 г. № 427 [9], т.е. более чем через полтора месяца; при этом уже через год недавно созданный Минкрым был упразднён [10].

Если рассматривать образованные в последние годы федеральные министерства, то можно перечислить упомянутое выше Министерство по делам Крыма (2014 г.), Министерство по делам Северного Кавказа (2014 г.), Министерство строительства и жилищнокоммунального хозяйства (2013 г.), Министерство по развитию Дальнего Востока (2012 г.), Министерство спорта, туризма и молодёжной политики (2008 г., преобразовано в 2012 г.), не считая различных созданных федеральных служб и федеральных агентств. В своё время одним только указом Президента Российской Федерации от 9 марта 2004 г. № 314 было образовано 5 федеральных министерств, 15 федеральных служб и 21 федеральное агентство, всего - 41 новый федеральный орган исполнительной власти. Для сравнения, с точки зрения появления новых федеральных министерств в США, то последние созданные департаменты - это Департамент государственной безопасности (US Department of Homeland Security, 2002 г.), Департамент по делам ветеранов США (US Department of Veterans Affairs, 1988 г.), Департамент образования США (US Department of education, 1979 г.). Таким образом, очевиден принципиально иной темп изменений структуры федеральных органов исполнительной власти.

Что касается российской системы федеральных органов исполнительной власти, приведённые изменения на этом не заканчиваются: на официальных порталах органов государственной власти, в СМИ с различной степенью интенсивности озвучиваются инициативы, идеи и предложения по созданию новых министерств, агентств и служб. Среди таких предложений, например, можно выделить возможность создания министерства по делам Арктики [11], министерства возобновляемых природных ресурсов [12], министерства науки и техники [13], министерства космоса [14], министерства семьи и демографии [15], а также федеральной службы пробации [16], Федеральной службы по надзору за безопасностью средств медицинского назначения и пищевых продуктов [17], федерального агентства по государственной службе [18] и ряда других органов исполнительной власти.

В категорию «преобразований» федеральных органов исполнительной власти можно включить несколько направлений изменений. Так, во время рассмотренной уже реформы 2004 года значительно сократилось количество типов органов исполнительной власти, соответственно, прекратившие существование типы органов власти были преобразованы. Например, 
DOI: $10.7256 / 1811-9018.2015 .9 .15938$

При цитировании этой статьи сноска на доі обязательна

\section{Право и политика 9 (189) • 2015}

Государственный таможенный комитет был преобразован в Федеральную Таможенную службу. Причём данный процесс был именно преобразованием, а не переименованием, поскольку создаваемая ФТС России в результате реформы была лишена функций по нормативному правовому регулированию в установленной сфере деятельности и эти полномочия были переданы в существовавшее на тот момент Министерство экономического развития и торговли (однако, необходимо заметить, что такое положение вещей просуществовало до 2006 года, когда ФТС была выведена из под руководства Минэкономразвития России, и ей были переданы функции по выработке государственной политики и нормативному правовому регулированию в области таможенного дела).

Реорганизационные мероприятия в форме преобразований зачастую непосредственно связаны с упразднением одного органа исполнительной власти и передаче его функций из системы исполнительной власти. Причем в данном случае можно выделить несколько подтипов таких преобразований. Например, передача полномочий от федерального органа исполнительной власти другому государственному органу. Из недавних наиболее ярких примеров можно назвать передачу в 2013 году полномочий Федеральной службы по финансовым рынкам Центральному Банку [19]. Причём такой передаче полномочий предшествовало ещё одно реорганизационное мероприятие - в 2011 году к Федеральной службе по финансовым рынкам была присоединена Федеральная служба страхового надзора [20].

Другим примером преобразований, связанным с упразднением, при которых определённые функции государственного управления выводятся из системы органов исполнительной власти, может служить упразднение в 2008 г. Федерального агентства по атомной энергии [21] (Росатом) и передаче его полномочий Государственной корпорации по атомной энергии «Росатом», которая была создана в форме государственного некоммерческого юридического лица. Причём, необходимо отметить, что правовой статус этого некоммерческого юридического лица, в отличие от федерального органа исполнительной власти, уже регулируется Федеральным законом от 1 декабря 2007 г. № 317-Ф3 «О государственной корпорации по атомной энергии «Росатом» [22], т.е. в данном случае применяется более высокий уровень правового регулирования. Более того, в соответствии со ст. 8 № 317-ФЗ «Росатом» наделяется полномочиями по нормативному правовому регулированию в установленной сфере деятельности, т.е. некоммерческое юридическое лицо в результате преобразований было наделено функцией, аналогичной федеральному министерству.

В структуре федеральных органов исполнительной власти встречаются и примеры «полностью» упразднённых органов власти, при этом процесс упразднения в последние годы в основном затрагивает федеральные службы и федеральные агентства, в некотором смысле перекраивая общую задумку административной реформы, т.е. «возвращая» функции по государственному контролю и надзору, предоставлению государственных услуг обратно в федеральные министерства. Примерами таких упразднений с возвращением функции по предоставлению государственных услуг могут служить упразднённые в 2010 году Федеральное агентство по науке и инновациям и Федеральное агентство по образованию [23], функции которых были переданы в Минобранауки России; а части передачи функций по государственному контролю и надзору - упразднение Федеральной службы по надзору за соблюдением законодательства в области охраны культурного наследия (Росохранкультура) и передаче её функций Министерству культуры [24].

Среди нерассмотренных форм изменений в структуре федеральных органов исполнительной власти остаётся переименование, которая при кажущемся внешнем относительно несложном претворении в жизнь и отсутствием сущностного влияния на механизм государственного управления, в то же самое время предусматривает значительные изменения в корреспондирующих нормативных правовых актах, а также большой объём административно-хозяйственных мероприятий, связанных с переименованием органа власти.

Таким образом, в статье рассмотрены, систематизированы и проиллюстрированы примерами различные формы изменений системы и структуры федеральных органов исполнительной власти России, правовые основы функционирования которой имеют подзаконный характер, что позволяет, с одной стороны, главе государства оперативно реагировать на изменяющиеся условия государственного управления, но, с другой стороны, создаёт предпосылки для нестабильности системы и структуры федеральных органов исполнительной власти, снижает возможность контроля правовыми средствами органов исполнительной власти со стороны законодательной власти, создаёт политическую опасность того, что смена высшего руководства страны может привести к кардинальными и субъективно обусловленным изменениям системы и структуры органов 
исполнительной власти. В связи с этим приведённые в статье обоснования в очередной раз ставят вопрос о необходимости принятия федерального закона «О федеральных органах исполнительной власти», который бы позволил бы более прочно закрепить накопленный позитивный опыт функционирования федеральных органов исполнительной власти, а также снять политические риски.

\section{Библиография:}

1. Бараненков В.В. Гражданско-правовая личность органов государственной власти (к вопросу о юридических лицах публичного права) / В.В. Бараненков // Государственная власть и местное самоуправление. - 2007. - № 6. - С. 3-6

2. Саввинова Ю.А. Проблемы, возникающие при реорганизации органов государственной власти / Ю.А. Саввинова // Современное право. - 2009. - № 12. - С. 42-44

3. О мерах по совершенствованию государственного регулирования в сфере финансового рынка Российской Федерации: Указ Президента Российской Федерации от 4 марта 2011 г. № 270 // Собрание законодательства Российской Федерации. - 2011. - № 10. - Ст. 1341

4. О структуре федеральных органов исполнительной власти: Указ Президента Российской Федерации от 17 мая 2000 г. № 867 // Собрание законодательства Российской Федерации. - 2000. - № 21. - Ст. 2168.

5. О системе и структуре федеральных органов исполнительной власти: Указ Президента Российской Федерации от 9 марта 2004 г. № 314 // Собрание законодательства Российской Федерации. - 2004. - № 11. - Ст. 945

6. Вопросы системы и структуры федеральных органов исполнительной власти: Указ Президента Российской Федерации от 12 мая 2008 г. № 724 // Собрание законодательства Российской Федерации. - 2008. - № 20. - Ст. 2290

7. О структуре федеральных органов исполнительной власти: Указ Президента Российской Федерации от 21 мая 2012 г. № 636 // Собрание законодательства Российской Федерации. - 2012. - № 22. - Ст. 2754

8. О Министерстве Российской Федерации по делам Крыма : Указ Президента Российской Федерации от 31 марта 2014 г. № 190 // Собрание законодательства Российской Федерации. - 2014. - № 14. - Ст. 1608.

9. О Министерстве Российской Федерации по делам Крыма : Постановление Правительства Российской Федерации от 10 мая 2014 г. № 427 // Собрание законодательства Российской Федерации. - 2014. - № 20. - Ст. 2536.

10. Об упразднении Министерства Российской Федерации по делам Крыма и Государственной комиссии по вопросам социально-экономического развития Республики Крым и г. Севастополя: Указ Президента Российской Федерации от 15 июля 2015 г. № 368 [Электронный ресурс] // Официальный интернет-портал правовой информации. - 2015. - 16 июля. - Режим доступа: http://www.pravo.gov.ru/

11. Нечаев В. Донской: «Создание министерства Арктики могло бы решить ряд проблем» [Электронный ресурс] / Вячеслав Нечаев // Известия. - 2014. - 4 декабря. - Режим доступа: http://izvestia.ru/news/580281

12. Писарёва К. Росрыболовство раскинуло сети на министерство [Электронный ресурс] / Ксения Писарева // Коммерсант. ru. - 2013. - 18 января. - Режим доступа: http://www.kommersant.ru/doc-rss/2106584

13. Российской науке нужны новые закон и министерство [Электронный ресурс] // РИА Новости. $-2014 .-5$ февраля. - Режим доступа: http://ria.ru/science/20140205/993240013.html

14. Путин не исключает создания министерства космоса [Электронный ресурс] // РИА Новости. - 2013. - 12 апреля. - Режим доступа: http://ria.ru/science/20130412/932267715.html

15. Мизулина поддерживает идею создания министерства семьи [Электронный ресурс] // РИА Новости. - 2013. - 30 июля. - Режим доступа: http://ria.ru/society/20130730/953010804.html

16. Перспективы создания службы пробации в России [Электронный ресурс] // Официальный сайт Уполномоченного по правам человека в Воронежской области. - 2013. - 27 марта. - Режим доступа: http://ombudsman-vrn.ru/index.php/201303-21-13-40-29/vzaimodeistvie-s-gosudarstvennimi-organami/343-perspektivy-sozdaniya-sluzhby-probatsii-v-rossii

17. В России создадут «мегарегулятор» потребительского рынка [Электронный ресурс] // Лента.ru/-2007. - 9 февраля. Режим доступа: http://m.lenta.ru/news/2007/02/09/regulate/

18. Медведев подумает над созданием федерального агентства по госслужбе [Электронный ресурс] // РИА Новости. - 2012. - 14 марта. - Режим доступа: http://ria.ru/society/20120314/594567716.html

19. Об упразднении Федеральной службы по финансовым рынкам, изменении и признании утратившими силу некоторых актов Президента Российской Федерации: Указ Президента Российской Федерации от 25 июля 2013 г. № 645 // Собрание законодательства Российской Федерации. - 2013. - № 30 (ч. 2). - Ст. 4086

20. О мерах по совершенствованию государственного регулирования в сфере финансового рынка Российской Федерации: Указ Президента Российской Федерации от 4 марта 2011 г. № 270 // Собрание законодательства Российской Федерации. - 2011. - № 10. - Ст. 1341

21. О мерах по созданию Государственной корпорации по атомной энергии «Росатом»: Указ Президента Российской Федерации от 20 марта 2008 г. № 369 // Собрание законодательства Российской Федерации. - 2008. - № 12. - Ст. 1112.

22. О государственной корпорации по атомной энергии «Росатом»: Федеральный закон от 1 декабря 2007 г. № $317-\Phi 3 / /$ Собрание законодательства Российской Федерации. - 2007. - № 49. - Ст. 6078

23. Вопросы Министерства образования и науки Российской Федерации: Указ Президента Российской Федерации от 4 марта 2010 г. № 271 // Собрание законодательства Российской Федерации. - 2010. - № 10. - Ст. 1057 
DOI: $10.7256 / 1811-9018.2015 .9 .15938$

При цитировании этой статьи сноска на dоі обязательна

\section{Право и политика 9 (189) • 2015}

24. Вопросы Министерства культуры Российской Федерации : Указ Президента Российской Федерации от 8 февраля 2011 г. № 155 // Собрание законодательства Российской Федерации. - 2011. - № 7. - Ст. 938

25. Борисов А.М. Реформирование системы органов исполнительной власти и новая схема государственного территориального управления // Административное и муниципальное право. - 2012. - 9. - С. 33 - 37.

26. Гончаров В.В. Проблемы и перспективы взаимодействия Федерального собрания Российской Федерации с федеральными органами исполнительной власти // Административное и муниципальное право. - 2010. - 3. - С. 43 - 47.

27. Бочарова Н.Н. Новеллы административно-правового статуса Центрального банка Российской Федерации в условиях административной реформы // Административное и муниципальное право. - 2013. - 11. - С. 1036 - 1038. DOI: 10.7256/19992807.2013.11.9835.

\section{References (transliterated):}

1. Baranenkov V.V. Grazhdansko-pravovaya lichnost' organov gosudarstvennoi vlasti (k voprosu o yuridicheskikh litsakh publichnogo prava) / V.V. Baranenkov // Gosudarstvennaya vlast' i mestnoe samoupravlenie. - 2007. - № 6. - C. 3-6

2. Savvinova Yu.A. Problemy, voznikayushchie pri reorganizatsii organov gosudarstvennoi vlasti / Yu.A. Savvinova // Sovremennoe pravo. - 2009. - № 12. - S. 42-44

3. Nechaev V. Donskoi: «Sozdanie ministerstva Arktiki moglo by reshit' ryad problem» [Elektronnyi resurs] / Vyacheslav Nechaev // Izvestiya. - 2014. - 4 dekabrya. - Rezhim dostupa: http://izvestia.ru/news/580281

4. Pisareva K. Rosrybolovstvo raskinulo seti na ministerstvo [Elektronnyi resurs] / Kseniya Pisareva // Kommersant.ru. - 2013. - 18 yanvarya. - Rezhim dostupa: http://www.kommersant.ru/doc-rss/2106584

5. Borisov A.M. Reformirovanie sistemy organov ispolnitel'noi vlasti i novaya skhema gosudarstvennogo territorial'nogo upravleniya // Administrativnoe i munitsipal'noe pravo. - 2012. - 9. - C. 33 - 37.

6. Goncharov V.V. Problemy i perspektivy vzaimodeistviya Federal'nogo sobraniya Rossiiskoi Federatsii s federal'nymi organami ispolnitel'noi vlasti // Administrativnoe i munitsipal'noe pravo. - 2010. - 3. - C. 43 - 47.

7. Bocharova N.N. Novelly administrativno-pravovogo statusa Tsentral'nogo banka Rossiiskoi Federatsii v usloviyakh administrativnoi reformy // Administrativnoe i munitsipal'noe pravo. - 2013. - 11. - C. 1036 - 1038. DOI: 10.7256/1999-2807.2013.11.9835. 